\title{
ANÁLISE DA DEMANDA POR DEFENSIVOS PELA FRUTICULTURA BRASILEIRA 1997-2000 ${ }^{1}$
}

\author{
EVARISTO MARZABAL NEVES ${ }^{2}$, MARIAM DAYOUB ${ }^{3}$, DIOGO SUZIGAN DRAGONE ${ }^{4}$
}

\begin{abstract}
RESUMO - Este estudo estima a demanda relativa por defensivos pela fruticultura brasileira, principalmente para banana, laranja, maçã, melão e uva, por dispêndio total e volume de princípio ativo por hectare, para o período de 1997 a 2000. Efetua, também, uma análise comparativa destas demandas com as obtidas para as principais culturas brasileiras (soja, milho, cana-de-açúcar e café), as quais são predominantes em termos de área cultivada e dominantes, em termos absolutos, nos dispêndios totais e volumes demandados por princípio ativo em defensivos no Brasil. Determina, ainda, em termos absolutos, a participação da fruticultura nos dispêndios totais e no consumo de princípio ativo, especialmente em acaricidas e fungicidas. Conclui sobre a importância da estimativa da demanda relativa para a fruticultura, que supera significativamente as principais culturas comerciais do País, fornecendo indicadores para o comportamento de mercado para as diferentes classes de defensivos pela fruticultura brasileira.
\end{abstract}

Termos para indexação: fruticultura, demanda relativa, defensivos, princípio ativo.

\section{FRUIT TREE DEMAND FOR CHEMICALS 1997-2000}

ABSTRACT - This study estimates for the Brazilian fruit trees, mainly banana, orange, apple, melon and grape, the relative demand for chemicals, considering total expenses and quantity demanded for active principle per hectare, from 1997 to 2000. It is also established a comparative analysis among this demand with ones made by the main Brazilian crops (soybean, maize, sugar cane and coffee), that are predominating in terms of grown area and dominating, in absolute terms, of chemicals total expenses and consume of active principle volume in Brazil. Yet, determines, in absolute terms, the importance of fruit trees in chemicals total expenses and active principle consume, especially acaricides and fungicides. It concludes, about the importance of estimated relative demand for fruit trees, that it is higher than the ones by the mainly commercial crops in the country, offering indicators for the demand and market behavior to chemicals different classes by the Brazilian fruit trees.

Index terms: fruit trees, relative demand, chemicals, active principle.

\section{INTRODUÇÃO}

No consumo de defensivos, a agricultura brasileira destaca-se, posicionando-se em $3^{\circ}$ lugar, precedida por Estados Unidos e Japão. Mundialmente, em 1999, as vendas de defensivos alcançaram US\$19,40 bilhões e, no Brasil, US\$2,35 bilhões (12,11\% do total mundial). Em 2000, os dispêndios totais com defensivos, no País, foram de US\$2,50 bilhões, uma elevação de 6,38\% em relação aos gastos totais em 1999 (SINDAG, 2001).

Esta posição de destaque deve-se, em parte, ao tamanho da área cultivada e das culturas plantadas num país com dimensões continentais. Quando se analisa o volume consumido de princípio ativo por hectare pelos principais países, em 2000, o Brasil perde algumas posições, situando-se em $8^{\circ}$ lugar, após diversos países europeus, em cujas áreas, bem menores do que a brasileira, a agricultura se desenvolveu há séculos (Tabela 1$)$.

TABELA 1 - Defensivos no mundo em 2000: volume consumido de princípio ativo pelos 12 principais países $(\mathrm{kg} / \mathrm{ha})$.

\begin{tabular}{lclclc}
\hline País & Consumo & País & Consumo & País & Consumo \\
\hline Holanda & 17,5 & Alemanha & 4,4 & Luxemburgo & 3,1 \\
Bélgica & 10,7 & França & 4,4 & Espanha & 2,6 \\
Itália & 7,6 & Reino Unido & 3,6 & Dinamarca & 2,2 \\
Grécia & 6,0 & Brasil & 3,2 & Irlanda & 2,2 \\
\hline
\end{tabular}

Fonte: Sindicato Nacional da Indústria de Produtos para Defesa Agrícolas-Sindag (2001).

No Brasil, essa posição de destaque no consumo, em termos de dispêndios efetuados e consumo de princípio ativo deve-se, principalmente, aos grãos, cereais e fibras e, mais especificamente, às culturas direcionadas a agroindústrias e exportações. Para a fruticultura, em termos de dispêndios totais, a participação relativa dos defensivos tem ficado entre 6 e $8 \%$ (Tabela 2) e variando de 13 a 17\% no volume total consumido de princípio ativo (Tabela 3), ambos dependendo, ainda, do desempenho da citricultura.
No Brasil, esta participação ainda pequena da fruticultura, principalmente nos dispêndios totais com defensivos, está fortemente associada ao tamanho da área cultivada que, nos últimos anos, tem permanecido entre 4,0 e 4,5\% do total brasileiro (Tabela 4).

Associando-se dispêndios totais e volume total consumido de princípio ativo pela fruticultura no País, as frutas brasileiras poderiam ganhar expressividade caso se determinasse a demanda relativa (quantidade gasta em US\$ ou volume consumido de princípio ativo em $\mathrm{kg}$, por unidade de área cultivada por hectare).

Este estudo visa analisar a demanda relativa da fruticultura brasileira, tanto em termos de dispêndios (US\$/ha), como em volume de princípio ativo (kg/ha), e sua evolução no período de 1997 a 2000.

Apoiando-se em outras pesquisas, efetua-se, também, uma análise comparativa da demanda relativa das principais culturas brasileiras com as obtidas neste estudo, em termos de dispêndios totais e volume total consumido de princípio ativo no Brasil. Como informação adicional, apresenta-se, para a fruticultura, os dispêndios totais e o consumo total de princípio ativo por classe de defensivos, para o período de 1997 a 2000 .

\section{MATERIALEMÉTODOS}

São utilizados dados secundários obtidos junto ao Sindicato Nacional da Indústria de Produtos para Defesa Agrícola-Sindag, para os dispêndios totais e os volumes de princípio ativo, totais e por classe de defensivos, para o Brasil, e à Fundação Instituto Brasileiro de Geografia e Estatística-Fibge, para a área cultivada com cada cultura agrícola no País.

Faz-se um cruzamento de dados e estatísticas do Sindag e da Fibge, para o período de 1997 a 2000, estabelecendo-se uma relação entre dispêndios totais (Tabela 2) e volumes totais consumidos de princípio ativo no Brasil (Tabela 3) com a área total cultivada no País, por fruta considerada (Tabela 4). Para a análise, o ponto de partida é 1997, pois foi neste ano que se estabeleceu a disponibilidade de dados para

1 (Trabalho 068/2002). Recebido: 23/02/2002. Aceito para publicação: 24/10/2002.

2 Professor Titular do Depto. de Economia, Administração e Sociologia, ESALQ/USP - CP: 9 - CEP: 13418-900, Piracicaba/SP.Fone (19) 3429-4119. E-mail: emneves@esalq.usp.br

3 Graduanda em Engenharia Agronômica, bolsista PIBIC/CNPq, ESALQ/USP. E-mail: mdayoub@esalq.usp.br

4 Pós-graduando em Economia Aplicada, ESALQ/USP. E-mail: dsdragon@ esalq.usp.br 
maçã, uva e laranja, e, desde 1999, para melão e banana. Outras frutas ainda aparecem agregadas nas estatísticas, sendo elas: abacate, abacaxi, caju, caqui, coco-da-baía, figo, goiaba, mamão, manga, maracujá, marmelo, melancia, pêra e pêssego. Para 1997 e 1998, banana e melão estão agregados em "Outras frutas".

TABELA 2 - Defensivos no Brasil: dispêndio total pela agricultura brasileira e por Fruteira, 1997-2000 (em milhões de US\$).

\begin{tabular}{lccccrrrr}
\hline \multirow{2}{*}{ Cultura } & \multicolumn{2}{c}{$\mathbf{1 9 9 7}$} & \multicolumn{2}{c}{$\mathbf{1 9 9 8}$} & \multicolumn{2}{c}{$\mathbf{1 9 9 9}$} & \multicolumn{2}{c}{$\mathbf{2 0 0 0}$} \\
\cline { 2 - 9 } & US\$ & $\%$ & US\$ & $\%$ & US\$ & \multicolumn{1}{c}{$\%$} & US\$ & $\%$ \\
\hline Banana & nd & - & nd & - & 3,517 & 0,2 & 2,840 & 0,1 \\
Laranja & 137,324 & 6,3 & 163,105 & 6,4 & 128,588 & 5,5 & 101,466 & 4,1 \\
Maça & 14,677 & 0,7 & 17,583 & 0,7 & 16,576 & 0,7 & 14,851 & 0,6 \\
Melão & nd & - & \multicolumn{1}{c}{ nd } & - & 2,964 & 0,1 & 2,032 & 0,1 \\
Uva & 8,130 & 0,4 & 9,505 & 0,4 & 9,567 & 0,4 & 9,090 & 0,4 \\
Outras frutas & 26,511 & 1,2 & 29,128 & 1,1 & 14,499 & 0,6 & 14,449 & 0,6 \\
Subtotal frutas & 186,642 & 8,6 & 219,321 & 8,6 & 175,711 & 7,5 & 144,728 & 5,8 \\
Outras culturas & $1.994,148$ & 91,4 & $2.338,529$ & 91,4 & $2.153,359$ & 92,5 & $2.355,232$ & 94,2 \\
\hline Total & $2.180,790$ & 100,0 & $2.557,850$ & 100,0 & $2.329,070$ & 100,0 & $2.499,960$ & 100,0 \\
\hline
\end{tabular}

Fonte: Sindag (2001). nd = não-disponível. Obs: para 1997 e 1998, os dados de banana e melão estavam agregados em "Outras frutas".

TABELA 3 - Defensivos no Brasil: consumo total de princípio ativo pela agricultura e por Fruteira, 1997-2000 (mil t).

\begin{tabular}{lccccrrrr}
\hline \multirow{2}{*}{ Cultura } & \multicolumn{2}{c}{1997} & \multicolumn{2}{c}{1998} & \multicolumn{2}{c}{$\mathbf{1 9 9 9}$} & \multicolumn{2}{c}{$\mathbf{2 0 0 0}$} \\
\cline { 2 - 9 } & mil t & \multicolumn{1}{c}{ m } & \multicolumn{1}{c}{ mil t } & \multicolumn{1}{c}{ mil t } & \multicolumn{1}{c}{$\%$} & \multicolumn{1}{c}{ mil t } & \multicolumn{1}{c}{$\%$} \\
\hline Banana & nd & - & nd & - & 0,205 & 0,2 & 0,166 & 0,1 \\
Laranja & 15,504 & 13,6 & 12,672 & 9,8 & 14,833 & 11,6 & 14,486 & 10,3 \\
Maçã & 1,112 & 1,0 & 1,851 & 1,4 & 1,473 & 1,2 & 1,472 & 1,0 \\
Melão & nd & - & nd & - & 0,095 & 0,1 & 0,077 & 0,1 \\
Uva & 0,560 & 0,5 & 0,694 & 0,5 & 0,843 & 0,7 & 0,634 & 0,5 \\
Outras frutas & 2,001 & 1,8 & 1,625 & 1,3 & 0,892 & 0,7 & 1,221 & 0,9 \\
Subtotal frutas & 19,177 & 16,8 & 16,842 & 13,1 & 18,341 & 14,4 & 18,056 & 12,9 \\
Outras culturas & 94,753 & 83,2 & 111,868 & 86,9 & 109,239 & 85,6 & 122,364 & 87,1 \\
\hline Total & 113,930 & 100,0 & 128,710 & 100,0 & 127,580 & 100,0 & 140,420 & 100,0 \\
\hline
\end{tabular}

Fonte: Sindag (2001). nd = não-disponível. Obs: para 1997 e 1998, os dados de banana e melão estavam agregados em "Outras frutas".

TABELA 4 - Brasil: área cultivada com fruteiras, 1997-2000 (mil ha).

\begin{tabular}{lrrrrrrrr}
\hline \multirow{2}{*}{ Cultura } & \multicolumn{2}{c}{$\mathbf{1 9 9 7}$} & \multicolumn{2}{c}{$\mathbf{1 9 9 8}$} & \multicolumn{2}{c}{$\mathbf{1 9 9 9}$} & \multicolumn{2}{c}{$\mathbf{2 0 0 0}$} \\
\cline { 2 - 9 } & \multicolumn{1}{c}{ mil ha } & \multicolumn{1}{c}{$\%$} & \multicolumn{1}{c}{ mil ha } & \multicolumn{1}{c}{$\%$} & mil ha & \multicolumn{1}{l}{$\%$} & mil ha & \multicolumn{1}{c}{$\%$} \\
\hline Banana & 546,4 & 1,10 & 536,4 & 1,07 & 536,4 & 1,03 & 533,6 & 1,01 \\
Laranja & 988,4 & 1,99 & $1.024,5$ & 2,05 & $1.029,8$ & 1,98 & 857,5 & 1,62 \\
Maçã & 26,5 & 0,05 & 26,6 & 0,05 & 28,6 & 0,06 & 30,0 & 0,06 \\
Melão & 13,7 & 0,03 & 13,9 & 0,03 & 11,5 & 0,02 & 11,4 & 0,02 \\
Uva & 57,0 & 0,11 & 61,1 & 0,12 & 60,5 & 0,12 & 59,8 & 0,11 \\
Outras frutas & 565,9 & 1,14 & 574,8 & 1,15 & 589,9 & 1,14 & 614,0 & 1,16 \\
Subtotal frutas & $2.198,0$ & 4,43 & $2.237,3$ & 4,48 & $2.256,8$ & 4,34 & $2.106,3$ & 3,97 \\
Outras culturas & $45.204,0$ & 91,14 & $45.485,5$ & 91,70 & $47.426,5$ & 95,62 & $48.827,3$ & 98,44 \\
\hline Total & $49.600,0$ & 100,00 & $49.960,0$ & 100,00 & $51.940,0$ & 100,00 & $53.040,0$ & 100,00 \\
\hline
\end{tabular}

Fonte: Elaborada pelos autores a partir de dados da Fibge (2001).

\section{RESULTADOS E DISCUSSÃO}

A Tabela 5 traz os volumes obtidos para a demanda relativa, medida em dispêndios por unidade de área cultivada (US\$/ha).

Verifica-se o expressivo gasto (US\$/ha) para a maçã, seguida por melão, uva e laranja, sempre acima de US\$100,00/ha. Por sua vez, a banana apresenta valor pouco significativo, abaixo de US\$10,00/ha.

Para evidenciar a expressividade da demanda relativa em termos de dispêndios/ha das frutas maçã, melão, uva e laranja, basta fazer uma comparação com as principais culturas brasileiras (Neves et al., 2001). Neves et al. (2002), para o ano 2000, em termos absolutos, constataram que soja, milho, cana e café despenderam em defensivos, por hectare, US\$ 64,24, US\$19,78, US\$38,01 e US\$70,54, respectivamente, enquanto maçã gastou US\$ 494,24/ha, melão US\$ 178,11/ha, uva US\$ 151,91/ha e a laranja, US\$118,33/ha, todas estas acima de US\$100,00/ha.

Como a área cultivada total é importante componente para os dispêndios em termos absolutos, quando se determina a demanda relativa por unidade de área, os valores assumidos se diferenciam. Por exemplo, tomando-se o ano 2000, dos US $\$ 2,5$ bilhões despendidos com de- fensivos no Brasil, soja, milho, cana-de-açúcar e café gastaram US\$ 879,5 milhões (35,18\%), US\$250,18 milhões (10,01\%), US\$ 185,5 milhões $(7,42 \%)$ e US\$ 161,5 milhões $(6,46 \%)$, respectivamente, perfazendo o percentual de 59,07\% do dispêndio total com defensivos no País. Porém, como a área cultivada em 2000 foi de 13,69 milhões de hectares para a soja; 12,65 milhões para o milho; 4,88 milhões para a cana; e 2,29 milhões de hectares para o café, a demanda relativa (US\$/ha) cai bastante no comparativo com as frutas.

TABELA 5 - Defensivos no Brasil: valores despendidos pelas fruteiras, 1997-2000 (US\$/ha).

\begin{tabular}{lcccr}
\hline Fruteira & $\mathbf{1 9 9 7}$ & $\mathbf{1 9 9 8}$ & $\mathbf{1 9 9 9}$ & $\mathbf{2 0 0 0}$ \\
\hline Banana & nd & nd & 6,56 & 5,32 \\
Laranja & 138,93 & 159,21 & 124,86 & 118,33 \\
Maçã & 554,46 & 662,23 & 579,84 & 494,24 \\
Melão & nd & nd & 258,66 & 178,11 \\
Uva & 142,54 & 155,57 & 158,06 & 151,91 \\
Outras frutas & 46,84 & 50,67 & 24,58 & 23,53 \\
\hline
\end{tabular}

Fonte: Elaborada pelos autores a partir do cruzamento de dados do Sindag e da Fibge (2001). Obs: para 1997 e 1998, os dados de banana e melão estavam agregados em "Outras frutas".

A Tabela 6 mostra a demanda relativa por princípio ativo. Neste caso, para as frutas, a ordem se altera, quando comparada com a demanda relativa que mensura volumes/ha. Em 2000, a laranja posicionou-se em $2^{\circ}$ lugar (16,89 kg/ha), precedida pela maçã (48,99 kg/ha), enquanto ocupou o $4^{\circ}$ lugar na análise anterior (Tabela 5).

Apoiando-se em Neves et al. (2002), pode-se inferir que a demanda derivada (kg de princípio ativo/ha) é maior nas frutas do que nas outras culturas analisadas (soja, milho, cana-de-açúcar e café). Em termos absolutos, para um total de 140,423 mil t, os consumos de princípio ativo por hectare por soja, milho, cana-de-açúcar e café foram de 46,274 mil t (32,95\%), 21,201 mil t (15,10\%), 11,337 mil t (8,07\%) e 9,085 mil t $(6,47 \%)$, respectivamente, perfazendo $53,59 \%$ do volume total brasileiro consumido de princípio ativo no ano 2000. Quando é determinada a demanda relativa, os valores para café, cana-de-açúcar, soja e milho foram, em kg/ha, de 3,97; 3,38; 2,32; e 1,68, respectivamente. Como a demanda relativa de princípio ativo foi de $48,99 \mathrm{~kg} / \mathrm{ha}$ para a maçã, 16,89 $\mathrm{kg} / \mathrm{ha}$ para a laranja, $10,60 \mathrm{~kg} / \mathrm{ha}$ para a uva e $6,75 \mathrm{~kg} / \mathrm{ha}$ para o melão, verifica-se que a quantidade consumida de princípio ativo por estas frutas, por unidade de área cultivada, é bem maior do que a de 4 culturas importantes da economia brasileira (soja, cana, café e milho).

TABELA 6 - Defensivos no Brasil: volume consumido de princípio ativo pelas fruteiras, $1997-2000(\mathrm{~kg} / \mathrm{ha})$.

\begin{tabular}{lccrr}
\hline Fruteira & $\mathbf{1 9 9 7}$ & $\mathbf{1 9 9 8}$ & $\mathbf{1 9 9 9}$ & $\mathbf{2 0 0 0}$ \\
\hline Banana & nd & $\mathrm{Nd}$ & 0,38 & 0,31 \\
Laranja & 15,69 & 12,37 & 14,40 & 16,89 \\
Maçã & 42,01 & 69,71 & 51,53 & 48,99 \\
Melão & nd & nd & 8,29 & 6,75 \\
Uva & 9,82 & 11,36 & 13,93 & 10,60 \\
Outras frutas & 3,54 & 2,83 & 1,51 & 1,99 \\
\hline
\end{tabular}

Fonte: Elaborada pelos autores a partir do cruzamento de dados do Sindag e da Fibge (2001). Obs: para 1997 e 1998, os dados de banana e melão estavam agregados em "Outras frutas".

Outro resultado interessante foi a determinação da participação relativa da fruticultura nos dispêndios totais em US\$ (Tabela 7) e no consumo total de princípio ativo em toneladas (Tabela 8) por classe de defensivo, para o período 1997-2000. Pela Tabela 7, verifica-se que a fruticultura, mesmo detendo apenas 4,0 a $4,5 \%$ da área cultivada total brasileira, teve dispêndios com fungicidas variando de $10 \%$ (2000) a 13\% (1997) do total gasto no Brasil e, com acaricidas, aquisições de $92 \%$ (2000) a 96\% (1997). Assim, fica evidenciado que a indústria de defensivos da classe dos acaricidas depende bastante da fruticultura, principalmente do desempenho da citricultura, cujos valores despendidos com acaricidas e fungicidas se retraíram nos anos 1999 e 2000, devido, 
principalmente, aos preços pouco remuneradores recebidos pelos citricultores.

Ao se tratar da participação relativa da fruticultura no consumo total brasileiro de princípio ativo por classe de defensivo (Tabela 8), verifica-se que sua quantidade demandada nos fungicidas é mais elevada na fruticultura do que no conjunto de outras culturas, chegando a ser quase 5 vezes maior, se comparada à área brasileira cultivada. Enquanto a área total com frutas não passou dos 4,5\% no período analisado (19972000), o consumo total de princípio ativo na classe dos fungicidas pela fruticultura ficou entre 20,8\% (2000) e 22,8\% (1999). Enfocando-se a classe dos acaricidas, verifica-se que o consumo da fruticultura brasileira por princípio ativo ficou ao redor de $95 \%$ do total consumido por todas as culturas brasileiras, o que corrobora a grande importância das fruteiras para esta classe de defensivos.

TABELA 7 - Brasil: dispêndios das fruteiras por classe de defensivos, 1997-2000 (US\$ milhão).

\begin{tabular}{|c|c|c|c|c|c|c|c|c|}
\hline \multirow[t]{2}{*}{ Classe } & \multicolumn{2}{|l|}{1997} & \multicolumn{2}{|l|}{1998} & \multicolumn{2}{|l|}{1999} & \multicolumn{2}{|l|}{2000} \\
\hline & US\$ milhão & $\%$ & US\$ milhão & $\%$ & US\$ milhão & $\%$ & US\$ milhão & $\%$ \\
\hline Herbicidas & $1.214,818$ & & $1.368,723$ & & $1.175,933$ & & $1.300,515$ & \\
\hline Frutas & 26,599 & 2,19 & 29,205 & 2,13 & 22,062 & 1,88 & 20,415 & 1,57 \\
\hline Fungicidas & 356,304 & & 436,235 & & 422,476 & & 380,418 & \\
\hline Frutas & 46,017 & 12,92 & 51,510 & 11,81 & 44,363 & 10,50 & 37,929 & 9,97 \\
\hline Inseticidas & 464,796 & & 581,693 & & 596,051 & & 689,953 & \\
\hline Frutas & 25,580 & 5,50 & 34,273 & 5,89 & 30,909 & 5,19 & 19,855 & 2,88 \\
\hline Acaricidas & 86,714 & & 105,619 & & 78,726 & & 65,560 & \\
\hline Frutas & 83,138 & 95,88 & 99,064 & 93,79 & 73,518 & 93,38 & 60,361 & 92,07 \\
\hline Outros* & 58,159 & & 65,579 & & 55,881 & & 63,512 & \\
\hline Frutas & 4,615 & 7,94 & 4,474 & 6,82 & 4,433 & 7,93 & 6,176 & 9,72 \\
\hline
\end{tabular}

Fonte: Elaborada pelos autores a partir de dados do Sindag (2001). *Outros = antibrotantes, reguladores de crescimento, óleo mineral e espalhante adesivo.

A Tabela 8 evidencia a significativa participação da fruticultura na classe de defensivos denominada "Outros", constituída por antibrotantes, reguladores de crescimento, óleo mineral e espalhante adesivo, indispensáveis no uso de quebra de dormência em fruticultura temperada, no raleio de frutas, na melhoria da qualidade dos frutos e no fato de o óleo mineral ser utilizado na bananicultura, no controle de doenças fúngicas, entre outros. Verificaram-se variações no total demanda do de princípio ativo na classe de defensivos "Outros" (a menor porcentagem na demanda total de princípio ativo foi de 6,76\% em 1998, mas atingiu $27,18 \%$ deste consumo em 1999), mas para o período analisado, na média, o consumo destes produtos pelas fruteiras foi de $20 \%$ do total demandado no Brasil, cerca de 5 vezes mais quando relacionada a participação percentual da fruticultura na área total cultivada no País.

Estes resultados, por classe de defensivos, acabam sendo bons sinalizadores da demanda da fruticultura por defensivos e facilitadores no dimensionamento do potencial de tamanho e volume de produção da indústria frente às variações ou evoluções da área cultivada com fruteiras no Brasil.

Algumas limitações, principalmente as referentes à não-disponibilidade de estatísticas e informações desagregadas, impediram análises mais detalhadas e específicas sobre a demanda por fatores de produção (no caso, os defensivos) pela fruticultura.

TABELA 8 - Brasil: consumo de princípio ativo pelas fruteiras por classe de defensivos, 1997-2000 (mil t).

\begin{tabular}{lrrrrrrrr}
\hline Classe & \multicolumn{1}{c}{$\mathbf{1 9 9 7}$} & \multicolumn{2}{c}{$\mathbf{1 9 9 8}$} & \multicolumn{2}{c}{$\mathbf{1 9 9 9}$} & \multicolumn{2}{c}{$\mathbf{2 0 0 0}$} \\
\cline { 2 - 9 } & Mil t & mil t & $\%$ & mil t & $\%$ & mil t & $\%$ \\
\hline Herbicidas & 61,885 & & 69,177 & & 68,131 & & 81,862 & \\
Frutas & 1,998 & 3,23 & 2,433 & 3,52 & 1,977 & 2,90 & 1,982 & 2,42 \\
Fungicidas & 17,369 & & 19,993 & & 20,168 & & 19,072 & \\
Frutas & 3,938 & 22,67 & 4,325 & 21,63 & 4,599 & 22,80 & 3,961 & 20,77 \\
Inseticidas & 16,218 & & 20,390 & & 19,231 & & 19,447 & \\
Frutas & 2,214 & 13,65 & 2,101 & 10,30 & 1,619 & 8,42 & 1,295 & 6,66 \\
Acaricidas & 9,835 & & 7,612 & & 9,676 & & 8,935 & \\
Frutas & 9,348 & 95,05 & 7,203 & 94,63 & 9,325 & 96,37 & 8,615 & 96,42 \\
Outros* & 8,626 & & 11,540 & & 10,379 & & 11,107 & \\
Frutas & 1,669 & 19,35 & 0,780 & 6,76 & 2,821 & 27,18 & 2,203 & 19,83 \\
\hline
\end{tabular}

Fonte: Elaborada pelos autores a partir de dados do Sindag (2001). *Outros = antibrotantes, reguladores de crescimento, óleo mineral e espalhante adesivo.
Esta deficiência é explicada por diversos fatores. Primeiro, a importância econômica da fruticultura ainda é relativamente pequena, exceção à citricultura, quando comparada com a economia de outras culturas (grãos, cereais, fibras), que ganham espaço não somente pela extensão da área cultivada, mas também pela relevância na economia do agronegócio e na balança comercial do País, carreando consideráveis divisas, e pelos impactos socioeconômicos, alocativos e distributivos. A área com fruteiras não ultrapassa, ainda, 4,5\% da total cultivada no Brasil.

Segundo, as características próprias da fruticultura brasileira, por ora preferencialmente voltada ao mercado interno, estabelecem diversos sistemas de produção, tanto para a fruticultura tropical, quanto para a temperada, com considerável diversidade de espécies, cultivares e variedades, impondo, de acordo com as condições edafoclimáticas e topográficas, sistemas regionais diferenciados de condução e manejo, tanto em escalas de subsistência como comerciais.

É esperado, mediante o desenvolvimento de uma cultura exportadora para as frutas de mesa, a aplicação de técnicas gerenciais modernas e de qualidade, buscando atingir os gostos e as preferências dos consumidores internacionais. Isto já vem ocorrendo, vide o salto de $100 \%$ nas exportações brasileiras de frutas de mesa, que, em apenas 5 anos, passou de US\$ 109 milhões em 1997 para US\$ 215 milhões em 2001, com o predomínio das mangas (US\$ 50,8 milhões, 23,63\%) e dos melões (US\$ 39,3 milhões, 18,28\%), tendendo a intensificar-se nos anos subseqüientes.

Desta forma, esta importância que a fruticultura brasileira vem ganhando, começa a chamar a atenção de órgãos, empresas e entidades relacionados aos seus sistemas de produção, pois o avanço tecnológico e o crescimento na área plantada com frutas são importantes sinalizadores para estudos e análises das especificidades de cada fruta, do potencial do volume de produção e das estratégias de mercado das indústrias de insumos. Daí a dificuldade momentânea de compreender as especificidades das frutas de importância econômica nos dias de hoje e que se encontram, por enquanto, agrupadas em "Outras frutas".

Mesmo diante destas limitações, este estudo sinaliza que maiores atenções particulares devem ser dadas a determinadas frutas, devido à força que adquire quando se analisam suas características individuais na demanda por fatores de produção. Foram os casos de maçã, laranja, melão e uva, que, num comparativo com importantes culturas comerciais, como soja, cana-de-açúcar, milho e café, despendem mais, na média, em defensivos, e requerem maior volume de princípio ativo por hectare, principalmente nas classes acaricidas, fungicidas e "Outros" (reguladores de crescimento, antibrotantes, óleo mineral e espalhante adesivo) do que as culturas relacionadas. Estas ganham importância, em termos absolutos, nos valores despendidos e no consumo de princípio ativo devido, principalmente, ao tamanho da área cultivada no Brasil. Estas culturas (soja, cana-de-açúcar, milho e café), no ano 2000, ocuparam 63\% do total da área cultivada no Brasil, estimada em 53 milhões de hectares.

Ademais, este estudo atenta para um esforço conjunto de agregar pesquisadores das áreas biológicas e tecnológicas da fruticultura com os das áreas sociais, principalmente os da economia e administração para melhor interpretação, compreensão e cooperação na análise de estatísticas e economias da fruticultura.

\section{REFERÊNCIASBIBLIOGRÁFICAS}

\section{FUNDAÇÃO INSTITUTO BRASILEIRO DE GEOGRAFIA EESTATÍS-}

TICA/FIBGE. Estatísticas de área cultivada: anos 1997 a 2000. In: www.ibge.gov.br.

NEVES, E.M.; DRAGONE, D.S.; DAYOUB, M. Demanda por defensivos na citricultura: análise comparativa com outras culturas comerciais. Revista Laranja, CCSM-IAC, Cordeirópolis, v.22, n.2, p.285-297, 2001. NEVES, E.M.; DAYOUB, M.; DRAGONE, D.S. Demanda por fatores de produção na citricultura: fertilizantes e defensivos. Revista Laranja, CCSM-IAC, Cordeirópolis, v.23, n.1, p.37-56, 2002.

SINDICATO NACIONAL DA INDÚSTRIA DE PRODUTOS PARA DEFESA AGRÍCOLA/SINDAG. Estatísticas para o setor de defensivos: 1997 a 2000. In: www.sindag.com.br. 